\title{
Vegetable Variety Trials: An Administrative Point of View
}

Daniel J. Cantliffe

\begin{abstract}
Additional IndeX words. land grant university, seed industry, plant breeding
Summary. Since the establishment of the land-grant systems in the late 1800s, universities and experiment station systems have sought out and tested vegetable germplasm for its suitability in regional and local areas across the United States. The private seed industry continued to grow, both in number and volume of sales through the early half of the twentieth century. It was during this time that many of the public breeding programs at land-grant universities began corollary plant breeding programs in variety development for vegetables. For many years it was a cooperative coexistence between the private seed industry and the public programs, wherein the seed industry derived much of its germplasm for new variety releases from the public sector. Beginning in the 1970s, the numbers of public breeders began to decline, while the numbers, especially of $\mathrm{PhD}$ plant breeders in the private sector, began to proliferate. Throughout this 100-year period university personnel were actively involved in vegetable variety trials, both on main campuses as well as at experiment stations, and in many cases in locales in various counties through cooperative efforts with county agents. Up through this period much credit could be given to individual faculty members for their involvement in such endeavors. In the past 10 to 20 years, many things have changed in university operations and perspectives, namely faculty are only given credit for refereed publications, regardless of the area in which they work. Moreover, they must constantly procure money to support their programs. In the past, vegetable variety testing generally did not lead to refereed publications and was not supported by the industry. Moreover, as previously mentioned many of the public programs in germplasm improvement for vegetables across the United States have ceased, thus ending a direct need for variety testing to support these programs. The critical issue for today's faculty is the relative importance of variety testing and delivering information to the general public versus how they would support such a program and eventually get academic credit for conducting such a program.
\end{abstract}

\footnotetext{
The theme of this workshop relates to various aspects of not only conducting variety trials, but how and where they should be published. As the title of the workshop states, many times variety trials with vegetables have been confined to reports coming directly from the various research stations and/or departments where the work has been conducted. This generally limits the audience to a local and sometimes regional group. From an administrative point of view I feel it would be best to exploit diversification of avenues through which information is delivered to the public. At public institutions, due to their very nature, this should be the primary goal-not only to develop the information, but to be sure that the information is disseminated to all intended audiences.
} 
There are several questions that should be addressed before one considers where the information should be published. As a general viewpoint, if there is more than one source for the material, the publication(s) for the target audience must usually be broadened. The first question is what are the goals for the work? Why are you doing the work? What do you expect to obtain from the work? Who will benefit from the information obtained? It is very important to keep in mind that although the variety trials that are being conducted might be for a specific location, they may in fact report important information that can be utilized by individuals at distant locations, and in fact, in other countries. One must ask their self under the goals for the work what is the need for the work and also who will benefit from the work? If the individual scientist can answer these questions, then where and how they publish becomes very easy.

In 2001, faculty members must also answer these questions: 1) how will I finance the work, and 2) how will I get academic credit for the work? Days have long since passed when faculty were given any sums of money to conduct research programs in landgrant universities. Since the 1990s, it has been imperative that all faculty develop their own source of funding to run their program. This has developed into obtaining funds from competitive grants, foundations, growers, and/or various commercial/industry partners. Financing vegetable variety trials can be very expensive when one considers the need for land, resources to produce the crop, including irrigation, and most importantly labor to grow and harvest the $\operatorname{crop}(\mathrm{s})$. Further, there is generally a volume of work associated with analyzing the data and publishing it. Vegetable seed companies, especially over the past 20 years, have been continually bought and sold and have developed into large corporate entities few in number. In the United States none of the large seed companies are owned by U.S. companies. The movement to a large seed company mentality also brings movement towards global marketing, and thus, seed companies are not so interested anymore in strictly local results. Also, large corporate seed companies are interested in obtaining information from a diversity of sources on a global basis, and must spread their sometimes meager resources for financing such research, resulting in a very low level of support for individual variety testing programs. Further, it has been my experience that it is extremely difficult to find grower groups to finance vegetable variety trials, however, some grower groups place this type of information for certain commodities at the forefront of their needs for new information.

Credit for work that faculty complete under state experiment station systems must mean that it can be counted for tenure and/or promotion. Tenure and promotion review boards tend to count only refereed publications. Depending on the individual's appointment, some credits are given for non-refereed publications, but those credits become meager if those review boards are only counting local station reports. Thus, it is imperative that faculty at land-grant institutions develop credible public delivery systems that will ensure the dissemination of objectively gathered information.

If someone were to ask me "Can I get tenure and/or promotion doing vegetable variety trials?" my immediate answer would be "No, there would be absolutely no way that you could obtain tenure and/or promotion by exclusively doing vegetable variety trials." There is good reason for this. Promotion and tenure is based on excellence in teaching, research, and/ or service. Vegetable variety trials generally do not take a large amount of intellectual input. Basically, if one is doing a variety trial on slicing cucumbers (Cucumis sativus), they would contact individual seed companies to hopefully obtain new germplasm as well as existing germplasm to place in a companion test. Hopefully, the researchers would also put in some type of standard variety as controls that growers are commonly using in the area. The type of data derived generally comes after planting the crop, and most likely would be related to yield and in the case of cucumbers, possibly fruit quality. From this, comparisons among the data are presented. Thus, when tenure and promotion boards review packages consisting solely of intellectual information at this level, they tend to discredit the work as scholarly research. Under service, especially for people with primary Ex- tension appointments, this may be a very important part of their job, especially if they are located at research centers off the main campus. In this case it is best for the unit administrator to write up the need and importance for the work, but in no instance in my career have I seen individuals in the modern day obtain tenure and/or promotion when a predominant portion of their research or extension program is generated from variety trials, regardless of where they are located.

Thus, for enterprising faculty who feel that there is an absolute need for vegetable variety trials in their program, they should plan to develop a protocol and a marketing scheme for their administrators and others based on the needs and the benefits of the work. Total financing of the trial cannot generally come from one source, but can easily be directed over a series of sources. Firstly, funding the research can be from sources such as directly through the experiment station or extension service, via seed companies, and via grower or processor involvement; it can be through assistance at the county agent or county extension level, especially when working on variety trials in growers fields (gift-in-kind); or it can be through industry, USDA, or other sources combined to obtain the financing to conduct the trial(s). These sources many times can offset a great portion of the needs for funding the various aspects for these particular trials, especially labor.

With regard to publication and academic professional credit, it is many times best for the researcher to consider immediately publishing variety trial results in a format that can be delivered to grower groups in the local production area or region. In northern areas this is extremely important as variety trials can be summarized in the fall and the information can be delivered during meetings in the winter. In southern locations this is an ongoing process, 12 months of the year, with meetings being integrated with work in progress. The importance here is getting the information out as soon as possible. This can be in the form of station reports (Cantliffe et al., 1973), factsheets, memos, etc. At the same time the information should be placed on the Internet (http://edis.ifas. ufl.edu), wherein extension personnel (as well as growers or processors), both 
in the locale and nationally, can obtain the information. Credit should be given to the individual scientist for both of these types of publication outlets. Many times organizations such as the University of Florida summarize vegetable variety trials on an annual basis (Maynard and Olson, 2001). This takes longer to accumulate the information and then to publish and deliver, but this should also be a part of the information delivery system. Sometimes trade journals will be very interested in the information as it relates to specialty crops, minor crops, and other interesting things for their grower audiences. We find that publications like the American Vegetable Grower, with in excess of 30,000 subscribers, has issues each year dedicated to new products, crops, and varieties (American Vegetable Grower, 2000). Another source would be to deliver the information as part of variety recommendations in commercial vegetable production guides (Maynard and Olson, 2000).

In reviewing at this information, it seems apparent in this day and age that faculty would most want to get publications out of the same trials through a refereed peer-reviewed system. This publication outlet for the information is one generally not associated with direct delivery to growers or county extension personnel. Moreover, in order to get accepted into peer-reviewed refereed journals, the information must be more than simple straightforward variety trials (i.e., looking at 30 different varieties to see which variety yields more or has better fruit quality or may have better pest resistance). Thus, faculty of the $21^{\text {st }}$ century should consider incorporating ad- ditional scientific aspects into the variety trial to give information related to larger problems. Some examples of this might be someone conducting a potato (Solanum tuberosum) variety trial wherein they look for germplasm that is more efficient in nitrogen utilization so they might superimpose in the trial several levels of nitrogen and try to find varieties that grow and yield and have high quality under conditions of less nitrogen or water, or any other variable that you might want to add. Additional data collection would be necessary. We have looked, for instance, in the Everglades for sweet corn (Zea mays) germplasm that can grow and yield with a lower input of phosphorus because of the potential for phosphate pollution on the organic soils of Palm Beach County, Fla. Finding such germplasm can greatly benefit the plant breeder in developing more phosphate-efficient corn lines. At the same time, producers can use the new germplasm to alter their phosphate fertility practices.

Recently during the last few years HortTechnology has accepted papers which have been peer reviewed, and thus are refereed, and centered on variety selection for various traits or conditions as mentioned above (e.g., Pauli et al., 2000). Again, this is an excellent co-feature of developing information from variety trial research. Hort Technology targets a diverse audience including extension, industry and to some extent grower personnel. Most importantly, it is global in its delivery. I fully believe that the process of conducting variety trials at state experiment stations is extremely important and must continue. Additionally, I believe that financing the variety trials can be done from a myriad of sources as previously discussed in this paper. Finally, I believe it to be inherent that we as scientists look to as many avenues as potentially possible to deliver the information. For these reasons I believe that station reports are important as are extension electronic outlets, as are newsletters, as are potentially extension production guides, and most important to $21^{\text {st }}$ century faculty, new refereed publications. Thus, a faculty can position themselves to get three to five information outlet sources from the same variety trial, and thus, tap into a diverse audience that would range from the commercial grower and the university professional to the extension agent and seed company employee. In this case, the information is not only scientifically viable, but it is received more widely by local, regional, national, and global audiences.

\section{Literature cited}

American Vegetable Grower. 2000. Annual vegetable variety showcase. Amer. Veg. Grower 38(11):29-38.

Cantliffe, D.J., P. Goodwin, V.W. Nuttall, J. Metcalfe, H. J. Heinz, and J. Ingratta. 1973. Ontario pickling cucumber cultivar trails. Hort. Expt. Sta., Simcoe, Ont., Canada.

Maynard, D.N. and S.M. Olson. 2000. Vegetable production guide for Florida. Fla. Coop. Ext. Serv. Ext. Publ. SP-170.

Maynard, D.N. and S.M. Olson. 2001. Vegetable variety trial results in Florida for 2000. Fla. Coop. Ext. Serv. Circ. S-396.

Pauli, R.E., G. Uruu, and A. Arakaki. 2000. Variation in the cooked and chipping quality of Taro. HortTechnology 10:823-229. 